\title{
Invitation cards on the table
}

\author{
$\mathrm{R}$ W SMITHELLS
}

It is a privilege to lecture to colleagues, an honour to be invited, and a lot of hard work to do properly. The audience should expect an informative presentation. The lecturer should expect an informative invitation.

I am prompted to propose the use of standardised letters of invitation by several experiences, of which a recent example may be summarised as follows:

January: telephone call from Professor X, St Saviour's Hospital, London, saying, "Will you speak at a symposium in July?" (Agreed.)

February: confirmatory letter requesting title and offering expenses and small honorarium. (So far, so good.)

April: provisional programme received. Covering letter requests 500 word summary. "We are also intending to publish the full proceedings. Will you therefore..." (Not so good.)

May: summary sent to Professor X.

June (early): letter from Jones Laboratories: "We have the pleasure of collaborating with Professor X... Please let us have an abstract... In addition, we will be requiring a full manuscript... (Worse.)

June (late): letter from Jones Laboratories: "It is proposed to make recordings of the various talks for sale to delegates..." (Beyond reason.)

On arrival at meeting: note registration desk and lecture hall seats reserved for the press. (Not cricket.)

To be fair to a lecturer he needs to know precisely and entirely what is being asked of him at the first approach. The relevant information depends in part on whether the lecture is for a local postgraduate meeting or a major national or international gathering. Two letters of invitation are therefore presented: tourist and executive class. Some of the items included may appear spurious, but truth is stranger than fiction.

\section{Letter A: tourist class}

Dear...

I am writing to invite you to lecture in our postgraduate centre on (date) at (time).

We would like you to speak on (specified subject) or a subject of your choice. I enclose last year's lecture programme so that you can see what topics in your field have been covered recently.

We would like you to speak for (duration), after which there will/not be time for discussion.

The audience normally includes doctors/nurses/porters. [NB: Do not predict the size of the audience, or predict about $25 \%$ of average attendance.]

Projection facilities are available for slides/overheads/videotapes.

We shall/not be able to offer you lunch/supper before/after your lecture.

We shall/not pay you a lecture fee (of $£$ ).

A parking place has/not been reserved for you.

A drug company will be responsible for the food/the drink/your fee.

Yours sincerely...

\footnotetext{
University Department of Paediatrics and Child Health, The General Infirmary, Leeds LS2 9NS
}

R W SMITHELLS, MD, FRCP, professor of paediatrics

\section{Letter B: executive class}

Dear...

I should be pleased if you would agree to contribute to a conference/symposium/workshop on (topic or title) to be held at (venue) on (date).

I should like you to speak on (specified subject). I enclose the draft programme so that you can see how your contribution would fit in with the others.

You will see that your talk should not exceed (duration).

Time has been programmed for discussion immediately after your paper/at the end of the session.

The conference is intended primarily for general physicians/school doctors/community nurses/final year medical students.

Projection facilities are available for slides/overheads/videos/film

Conference languages will be English/Swahili/Hungarian. There will/not be simultaneous translation.

The conference can/not pay your travelling expenses.

We shall/not be paying a lecture fee $($ of $£ / \$)$.

You will/not be our guest throughout the conference.

You are/not expected to pay the registration fee.

The press may/will not be present.

^We would like a title for your talk by (deadline) for inclusion in the published programme.

*We would like a summary of your talk, not exceeding (numbers of words by (deadline) to circulate to participants before/at the conference.

*We intend to publish the proceedings and would like a fully referenced version of your paper, not exceeding (number of) words by (deadline).

*We propose to record your lecture and will want you to convert the typed version into readable English.

$\star$ The meeting is sponsored by a number of drug companies who wil be financially responsible for your expenses/the drink/the name badges/everything.

^You are welcome to bring your wife/husband at our/your expense

Yours sincerely...

$\star$ Delete if inappropriate.

\section{Optional extras}

Postgraduate tutors with a lively sense of humour might consider the following optional extras:

We are asking you because our $1 \mathrm{st} / 2 \mathrm{nd} / 3 \mathrm{rd}$ choice speakers were unable to accept.

The room in which you will be speaking was designed as a lecture room/nurses' common room/dance hall/sick bay.

We will/not know where to find the projection room key/the spare bulb/the pointer.

You will/not be repeatedly interrupted by bleeps and the consequent comings and goings of junior staff.

Although your lecture is not due to finish until (time) people will actually start drifting away from (time) pm to start clinics/play golf/go home.

In order to assist the chairman in introducing you could you let me have a note of your full name, qualifications, present and previous posts held, honours and distinctions (if any), and the titles of three recent publications.

In order to assist one of our senior members in preparing a spontaneous vote of thanks could you let me have a brief summary of your talk as his hearing is not what it was. 